Article

\title{
The Prevalence of Rough Sleeping and Sofa Surfing Amongst Young People in the UK
}

\author{
Anna Clarke \\ Cambridge Centre for Housing \& Planning Research, Department of Land Economy, University of Cambridge, Cambridge, \\ CB3 9EP, UK; E-Mail: acc44@cam.ac.uk
}

Submitted: 22 February 2016 | Accepted: 26 July 2016 | Published: 20 October 2016

\begin{abstract}
Whilst data on statutory homelessness is well recorded in the UK, there is a lack of data on informal homelessness (such as 'sofa surfing') and rough sleeping, other than that which relies on partial information and street counts. This paper presents findings from a recent online survey of young people and helps to fill this gap. It found that rates of sofa surfing and rough sleeping among young people were much higher than previously thought. Twenty-six percent of young people (aged 16-25) had slept rough at some point in their life and 35 percent had 'sofa surfed' (stayed with friends or family on their floor or sofa because they had nowhere else to go). The paper explores the implications of this for how we conceptualise homelessness. It suggests that homelessness may often be neither cause nor consequence of wider forms of exclusion, but that we may need to explore further the factors that enable some people to move swiftly out of homelessness more easily than others.
\end{abstract}

\section{Keywords}

boomerang generation; hidden homelessness; rough sleeping; sofa surfing; street homelessness; youth homelessness

\section{Issue}

This article is part of the issue "Homelessness and Social Inclusion", edited by Isobel Anderson (University of Stirling, UK), Maša Filipovič Hrast (University of Ljubljana, Slovenia) and Joe Finnerty (University College Cork, Ireland).

(C) 2016 by the author; licensee Cogitatio (Lisbon, Portugal). This article is licensed under a Creative Commons Attribution 4.0 International License (CC BY).

\section{Introduction}

In the UK, figures for the number of homeless people assisted by local authorities are collected, but other homeless people not in contact with homelessness services are particularly difficult to count. Those in contact with homelessness services, or who are sleeping on the street may be the 'tip of the iceberg' with many more experiencing homelessness but not using homelessness services, possibly because they rely on their own resources to solve their problems, or because they are unaware of the help available, or do not wish to use it.

This research, commissioned by youth homeless charity, Centrepoint, was part of a project estimating rates of youth homelessness throughout the UK (Clarke, Burgess, Morris, \& Udagawa, 2015). This paper analyses the findings from the part of the research into "hidden homelessness'-young people who experience home- lessness but are not in contact with any agencies, including sofa surfers and rough sleepers. These groups are hard to find and therefore to count.

This paper aims to help fill that gap and to complement existing data from other sources. It draws on a 2014 survey conducted online of over 2000 young people (aged 16-25) in the UK to establish how many have experienced sofa surfing or rough sleeping. Sofa surfing was defined as "where individuals stay with friends or members of their extended family on their floor or sofa as they have nowhere else to go". Rough sleeping was defined as having slept in a list of non-housing locations including parks and cars because they felt they had nowhere else to stay.

The high numbers found by this research support the need for the growing body of work around pathways into homelessness, focussing not just on immediate triggers of homelessness, but also on the factors that differenti- 
ate the young people who move swiftly out of homelessness and those who do not. It also presents a challenge to notions that homelessness is necessarily extreme or something that effects only the most socially excluded.

\section{Background}

To quantify homelessness, it is first necessary to define what it is that is being counted. Whilst people sleeping on the streets are more visibly homeless, there are a variety of precarious, insecure or unsatisfactory living conditions often termed "hidden homelessness" (Reeve \& Batty, 2011). The problem of definition has been a long running debate with little agreement or progress made on defining homelessness (Amore et al., 2011). The European Federation of National Organisations Working with the Homeless (FEANTSA) and the European Observatory on Homelessness have produced a classification system of different types of homelessness, termed ETHOS. However, this has been criticized for mixing up living situations, such as homeless shelters, with counts of people who are housed at present but at risk of future homelessness, such as people under threat of eviction or violence (Amore et al., 2011), reducing its utility as a definition that can be used to count homelessness at any one time. In practice, quantifying homelessness has tended to rely on data collected by governments-which is usually partial and relates mainly to specific categories of homeless people who are accessing services or have rights to be rehoused (Fitzpatrick, Pawson, Bramley, Wilcox, \& Watts, 2015). In the UK, some efforts have been made to count rough sleepers, but they are known to present only a partial picture of rough sleeping, especially outside London.

There have been few studies which have tried to look at the rate of hidden homelessness-such as sofa surfing-among young people. A 2007 Danish study found a high prevalence of hidden homelessness in Denmark (Benjaminsen \& Christensen, 2007). Sofa surfing has been mentioned in passing as an option used by women which may explain why there are fewer women found on the street (Reeve \& Casey, 2006; Weber Sikich, 2008); as preferable to hostels for gay young people (Cull, Platzer, \& Balloch, 2006) or as a precursor to more entrenched homelessness (Quilgars, Johnsen, \& Pleace, 2008). Disability has received relatively little attention in relation to homelessness, though it is known that adults who had childhood learning difficulties are over-represented among the homeless population (Patterson, Moniruzzaman, Frankish, \& Somers, 2012), with a recent UK study emphasising the need to understand disabled young people's role in shaping their own housing pathways (Mackie, 2012). Understanding the role of informal housing solutions such as sofa surfing could help develop this approach.

In the UK there are data collected from administrative sources on homeless people who are assisted by local authorities, but there appear to have been no real efforts made to systematically count people who are "hid- den homeless'-staying temporarily with friends or family members in what are very often quite precarious and insecure housing arrangements (Quilgars, Fitzpatrick, \& Pleace, 2011). A study of single homeless people using homelessness services found that the majority of homeless service users had experience of hidden homelessness (Reeve \& Batty, 2011) but we know very little about how many non-service users also have experience of hidden homelessness.

It is also as important to understand the duration and patterns of youth homelessness as it is to quantify it. This is particularly problematic with youth homelessness as is very often transient and connected to difficulties in making the transition from child to adult status (Chamberlain \& Johnson, 2013; Hutson \& Liddiard, 1994). A 2010 review of research (Quilgars, 2010) highlighted a 1998 research by the European Observatory on Homelessness which suggested that youth homelessness may be considered as a faltered or interrupted transition to adulthood which typically happens to vulnerable young people. It is well established that such transitions have become more protracted over the last two decades (Thomson, 2009) with the 'boomerang generation' gaining traction in the British press (Stone et al., 2014) and delayed independent household formation (Stone, Berrington, \& Falkingham, 2014), home ownership, later marriage, cohabitation and increased insecurity in labour markets.

Studies on the needs of the homeless population have often focussed on the ones who use services or approach local authorities for assistance in the UK. These have found homeless young people to have very high rate of vulnerability-missing school, mental health problems or a history of having run away from home as a child (Hodgson, Shelton, \& van den Bree, 2014; Quilgars et al., 2008). A high degree of overlap has been found between experience of homelessness and other domains of deep exclusion such as institutional care, childhood trauma, substance misuse, begging, street drinking, sex work, or 'survival' shoplifting (Fitzpatrick, Bramley, \& Johnson, 2012; Fitzpatrick \& Johnsen, 2011). A key aspect to debates around homelessness therefore concerns the nature and direction of causation. Do people become homeless as a result of other factor such as substance abuse or mental ill health? Or does homelessness contribute or directly cause these wider problems and difficulties for those who are living without a permanent home?

Whilst most studies suggest a degree of causation in both directions (Hodgson, Shelton, van den Bree, \& Los, 2013), the focus in recent years has been on preventing the tendency of homelessness to cause or worsen other difficulties by focussing on a Housing First approach (Filipovič Hrast, 2014; Gaetz, 2014). This approach challenges the notion that it is necessary for homeless people to tackle any wider problems before they can sustain a tenancy and instead endeavours to house people into permanent homes first, and then to support them to tackle any other difficulties, such as 
mental health or substance abuse. The Housing First approach has shown good results throughout Europe (Busch-Geertsema, 2014), and presented a major challenge to the previous linear "treatment first" approach used in the United States (Johnsen \& Teixeira, 2010). It is known that homeless people who suffer mental ill health or substance abuse tend to be homeless for longer than other homeless people, possibly because this leads them to become involved in a 'homeless sub-culture' associated with a street lifestyle to a greater extent than other homeless young people (Chamberlain \& Johnson, 2013). The impact of street lifestyle on mental health and substance abuse has also been highlighted (Kidd, 2004; McCay \& Aiello, 2013). The argument for a Housing First approach is, however, that wider difficulties do not in themselves prevent people from sustaining a tenancy, but rather that being homeless makes it harder to address other problems with proponents arguing that "becoming homeless may mean young people not only lose their families but other natural supports (friends, adults, extended family), and be forced to drop out of school" and can recover more quickly once housed (Gaetz, 2014). In other words, the underlying contention here is homelessness is more a cause than an automatic consequence of other difficulties.

The other major theme in policy around youth homelessness in the UK, as in much of Europe over the last ten years has been on homelessness prevention, rather than alleviation (Maher \& Allen, 2014). In the UK this approach is tied in with the development of local authority led services to prevent young people losing their homes including mediation with parents and access to alternative housing before an existing tenancy is terminated (Pawson et al., 2007). The success of this approach is also enhanced if homelessness is understood as being a cause of wider difficulties, which will therefore be avoided if homelessness is prevented.

\section{Data on Youth Homelessness in the UK}

Availability of data in the UK varies greatly between types of homelessness, and few data sources offer the ability to distinguish homelessness in general from youth homelessness among those aged under 25 (Homeless Link, 2014a).

Rough sleepers are notoriously difficult to count. Nevertheless, rough sleeping is a form of homelessness that has attracted much attention, and therefore efforts have been made throughout the UK to count rough sleepers, track them through support systems, and measure progress in reducing rough sleeping. These date back to the 1990 Rough Sleepers' Initiative. A key focus more recently has been on the 'No Second Night Out' project, which aims to ensure that no rough sleeper has to sleep out for more than one night after having made contact with services (Department for Communities and Local Government, 2011).

\footnotetext{
$\overline{{ }^{1} \text { www.broadwaylondon.org/CHAIN.html }}$
}

Street counts do not give a measure of the total number of people experiencing homelessness over the course of a year, because the duration of each person's rough sleeping is not known. However, they are accepted by the UK government as the most accurate method of measuring trends in rough sleeping over time (National Audit Office, 2005). They can also give some indication of the scale of rough sleeping in different locations, though this is dependent on rough sleepers' counts having taken place in comparable fashions.

Rough sleeping in London continues to receive the most political prominence and funding, though is by no means the only place where people sleep rough in the UK. Services for rough sleepers are better developed in London than in most other areas, and the Combined Homeless and Information Network (CHAIN) database is a key source of data here. CHAIN is a database for people who work with rough sleepers and the street population in London, maintained by a charity, St. Mungo's Broadway, and tracks individual rough sleepers across their contact with different services ${ }^{1}$. The latest report (St Mungo's Broadway, 2014) found there to be 6,508 known rough sleepers recorded in London in the year 2012-2013, of whom 773 were aged 16-25.

Outside of London, the government also produce snapshot figures for rough sleeping based on information collected by local authorities (Department for Communities and Local Government, 2014) The figures are based on street counts and also on other sources of information such as information from voluntary sector agencies in contact with rough sleepers, such as day centres. The autumn of 2014, street counts estimated that there were 2,744 rough sleepers on one night in England, an increase of 18 percent from autumn 2013, and of these, 2,002 were outside London. Just over a fifth of the rough sleepers counted in England were in London (742). There is much variation between authorities with some authorities, such as Cornwall, having higher rates of rough sleeping than most London boroughs, whilst in contrast 50 local authorities estimated or counted no rough sleepers at all on the night when data was collected. The DCLG data does not provide a breakdown by age group. However, data compiled by Homeless Link (Homeless Link, 2014b) does provide a split by age group, and suggests that ten percent of rough sleepers in London are aged 16-24, as are 20 percent of those outside London.

In Wales, a rough sleepers survey was undertaken in November 2015, the first for some years, and local authorities reported a total of 82 rough sleepers during one night, based on street counts of areas where rough sleepers were known to bed down. The survey also asked how many people were known to have slept rough in Wales over a two-week period, and this exercise produced a figure of 240 . No breakdown by age was given.

Rough sleepers' counts have not been consistently carried out in Scotland for over ten years. However, the previous housing circumstances of those assessed 
under the homeless persons' legislation when applying for housing are recorded (Scottish Government, 2013). These show that in 2013-2014 a total of 1,787 applicants had slept rough the night before they approached the council for housing assistance, 6.4 percent of all applicants. This figure is not broken down by age. The data also recorded 17 applicants who were classified as long term roofless (Scottish Government, 2014). These figures are not quite comparable to the CHAIN data on the numbers rough sleeping over a year, as they may include some double-counting (people who were assessed more than once in a year) and would also exclude any rough sleepers who did not approach a local authority, or who did so after having spent the previous night somewhere other than rough sleeping.

In Northern Ireland too, there is very little data on rough sleeping. The Northern Irish Housing Executive report that there are fewer than ten rough sleepers at any one time in Belfast and none elsewhere (Northern Irish Housing Executive, 2012); however, it is not stated when this count took place.

Previous research has tried to pull figures together for the UK as a whole and fill some of the gaps. A 2011 report estimated the number of young people experiencing homelessness in the UK during a year to be around 78,000-80,000 in 2008-2009, including 3,800 who slept rough at some point in a year (Quilgars et al., 2011), though acknowledges that this is likely to be a partial picture.

In short, all existing data on rough sleepers is dependent on the rough sleeper having been observed at some point by someone counting them either whilst rough sleeping, or shortly afterwards when they make contact with a support agency. No data exists on sofa surfing in the UK.

\section{Research Methods}

To help fill the gap in knowledge and find out more about young people's experiences of rough sleeping and sofa surfing, an online survey of 2,011 young people (aged 16-25) in the UK was drawn from a representative sample of UK adults. The survey was undertaken in September 2014 by ComRes, a leading polling company, with established panels known to be representative of the UK population, large enough to provide the required sample size of young people. The questions were designed by the academics leading the study, with input from Centrepoint, who founded the research, and also from ComRes who contributed technical expertise in questionnaire design. To avoid self-selection bias, the survey was advertised under the topic of "people" with the focus on homelessness only made apparent to young people once they responded to the survey. In total 17,605 invites were sent out, from which 5,537 respondents clicked through to the survey and of those there were 254 who were screened out (for instance on grounds of age), 349 who only completed part of the survey and 2011 who completed it. Online survey methods do exclude people without internet access, though data from the Office for $\mathrm{Na}$ tional Statistics (ONS) shows that 99 percent of 16-24 year olds were recent internet users by $2014^{2}$. Young people who were homeless at the time of the survey may have been less likely to have had reliable internet access, so could be somewhat under-represented.

The survey aimed to establish how many had experienced sofa surfing. Respondents were asked whether they had ever slept in a list of places such as in a park or in a car because they had nowhere else to stay (see Table 1 for the full list). They were also asked whether they had ever sofa surfed, which was defined for them as 'where individuals stay with friends or members of their extended family on their floor or sofa as they have nowhere else to go'-and if they had, whether they had done so in the last year, and the length of time they had spent sofa surfing.

The survey data was weighted by ComRes for region, age and gender and the full dataset supplied to the research team for analysis. In order to be sure of including only those who were actually homeless, the detail provided by those who answered that they had slept rough only 'in another place' and also those whose reason for having nowhere else to stay was given as 'other' were checked. Despite the question having asked about rough sleeping because you had nowhere else to stay some respondents gave reasons suggesting that they did have accommodation but were temporarily unable to get to it, or had chosen not to, for instance because they had lost their keys or missed the last train home. Any respondents whose answers indicated that they had slept rough through choice, whilst outside of the UK, or because they did have accommodation but that they were unable to access it were excluded from the rough sleepers group for the purposes of analysis. They have therefore not been counted as rough sleepers in the subsequent analysis. In total this led to 88 responses being recoded as not being rough sleepers.

\section{Findings}

\subsection{Rough Sleepers}

The 2,011 young people aged 16-25 surveyed were asked whether they had had to stay in one of a list of places because they had nowhere else to stay. They were then asked whether their experience of rough sleeping was in the last year, or longer ago. Table 1, below, shows the answers to this question:

Overall, the analysis suggested that 26 percent of young people in this age group had experience of rough sleeping because they were homeless, and 17 percent had done so within the last year. These have been termed hereafter as 'rough sleepers', though it should be noted that the definition of rough sleeping is a broad one

\footnotetext{
${ }^{2}$ www.ons.gov.uk/ons/publications/re-reference-tables.html?edition=tcm\%3A77-395602
} 
that includes not just those sleeping on the streets and in parks, but also those who have slept in cars or tents because they had nowhere else to stay.

A narrower definition of rough sleeping as including only those who were outdoors and open to the elements would include only those who had slept on the streets, in a car park or in a park or other open space. This narrower group of 'outdoors rough sleeping' comprised a total of 188 young people, or nine percent of all young people.

Young people answering yes to the question, where asked why they had had nowhere else to stay (Table 2).
Rough sleepers who had rough slept within the last year were asked how long they had slept rough for (Table 3).

From this information, it is possible to make minimum estimates of young people sleeping rough on any one night. Table 4 shows how this has been calculated.

If the young people answering this survey are representative of UK, the 0.53 percent sleeping rough on any one night would equate to 39,557 people (of a population of 7.45 million). This seems a very high figure in comparison to other sources, which are predominately based on rough sleepers counts and rough sleepers in contact

Table 1. "Have you ever had to sleep in one of these places because you had nowhere else to stay?".

\begin{tabular}{|c|c|c|c|}
\hline Response & Number & $\begin{array}{l}\text { Proportion of } \\
\text { all young people }\end{array}$ & $\begin{array}{l}\text { Proportion of } \\
\text { rough sleepers }\end{array}$ \\
\hline In a car & 292 & $15 \%$ & $55 \%$ \\
\hline In a car park* & 83 & $4 \%$ & $16 \%$ \\
\hline In a park or other open space* & 82 & $4 \%$ & $15 \%$ \\
\hline In a squat & 50 & $2 \%$ & $9 \%$ \\
\hline In a tent & 180 & $2 \%$ & $34 \%$ \\
\hline In an abandoned building & 53 & $3 \%$ & $10 \%$ \\
\hline In another place (please specify) & 10 & $1 \%$ & $2 \%$ \\
\hline On a night bus & 74 & $4 \%$ & $14 \%$ \\
\hline On the streets* & 95 & $5 \%$ & $18 \%$ \\
\hline Yes to any of the above & 533 & $26 \%$ & $100 \%$ \\
\hline Of whom had done so within the last year & 346 & $17 \%$ & \\
\hline Yes to any of the outdoor places (marked with ${ }^{*}$ ) & 188 & $9 \%$ & $35 \%$ \\
\hline I have never had to sleep in one of these places & 1,478 & $73 \%$ & - \\
\hline Total & 2,011 & $100 \%$ & - \\
\hline
\end{tabular}

Source: Clarke et al. (2015). Respondents could give more than one answer.

Table 2. "Which, if any, of the following reasons explain why you had nowhere else to stay? (All those who have rough slept)".

\section{Reason}

Proportion of those

My parents were unable or unwilling to accommodate me who slept rough

I left home due to the negative environment there

My friends or extended family were unable or unwilling to accommodate me

I split up from my partner

The place I was living was overcrowded

$110 \quad 21 \%$

$88 \quad 17 \%$

My tenancy came to an end through no fault of my own and I could not find

a new place to live

I was suffering from substance abuse (e.g. drugs or alcohol)

$79 \quad 15 \%$

$58 \quad 11 \%$

I was suffering domestic violence at my family home

$44 \quad 8 \%$

I am not a British citizen, and didn't know anyone in the UK I could stay with

I had to leave foster care / a children's home and had nowhere to go

I was suffering domestic violence from my partner

I had just left prison and had nowhere to go

$38 \quad 7 \%$

I was evicted from where I was living due to antisocial behaviour

(including noise, or damage to property)

Other (please specify)

\section{Total}

82

Source: Young people's survey, September 2014. Respondents could only give one answer. 
Table 3. Estimates of the average time rough sleepers aged 16-24 in the UK spent sleeping rough in the year to September 2014.

\begin{tabular}{|c|c|c|c|}
\hline & & Total & $\begin{array}{l}\text { Proportion of those who } \\
\text { slept rough in last year }\end{array}$ \\
\hline \multicolumn{2}{|c|}{ Number sleeping rough in last year } & 346 & $100 \%$ \\
\hline \multirow[t]{8}{*}{ Length of time slept rough } & 1 night & 137 & $40 \%$ \\
\hline & Between 1 night and a week & 119 & $34 \%$ \\
\hline & More than a week, but less than a month & 51 & $15 \%$ \\
\hline & More than one month, but less than three months & 20 & $6 \%$ \\
\hline & More than three months, but less than six months & 11 & $3 \%$ \\
\hline & More than six months, but less than a year & 6 & $2 \%$ \\
\hline & A year or longer & 1 & $*$ \\
\hline & Don't know & 1 & $*$ \\
\hline
\end{tabular}

Source: Young people's survey, September 2014. Respondents could only give one answer.

Table 4. Estimated number of people aged 16-24 rough sleeping on any one night in the year to September 2014.

\begin{tabular}{ll}
\hline & UK \\
\hline Number of young people answering survey & 2,011 \\
Number who have slept rough during the last year & 345 \\
Minimum number of nights spent sleeping rough in last year (by all rough sleepers) & 3,899 \\
Estimated number of young people in survey sleeping rough on any one night ${ }^{4}$ & 11 \\
Proportion of young people rough sleeping on any one night & $0.53 \%$ \\
\hline
\end{tabular}

Sources: Young people's survey, September 2014 and DCLG Mid-year population estimate; own calculations.

with agencies. It is difficult to estimate the margin of error here in statistical terms as the number sleeping rough on any one night (11) is based on responses from 345 people, but they have contributed unequally to this figure (a relatively small number of long-term rough sleepers constitute a large proportion of all rough sleeping). Nevertheless, even if only 11 rough sleepers had been responsible for all the rough sleeping, this would still give lower and upper confidence limits of 20,357 and 72,726 (at 95 percent confidence). Whilst a substantial range, even the lower figure is still greatly in excess of official estimates for rough sleeping. The fact that 345 people (not eleven) actually contributed something to the figure increases the level of confidence that the population total is closer to 39,557 . Whether these people can all be considered "homeless" is also worth considering, as for many the experience was very short lived reflecting one-off events.

It is unsurprising that this is higher than the published data; making contact with rough sleepers can be difficult for agencies, or people trying to count them especially if the rough sleeping is for a short duration or away from areas popular with rough sleepers. It is also important to note the variety of places that people reported they slept rough, as shown above in Table 2. Of those sleeping rough, 18 percent had slept on the streets, with a further 13 percent sleeping in a car park, park or other open space. Most of the rest had slept in a car, tent or night bus. This may mean that only around a third of the young people sleeping rough were in the more visible outdoor places where they might be more likely to be found by people doing street counts or working with rough sleepers. The extent of the rough sleeping of all sorts found in this survey is however very much higher than was expected.

Even if we focus only on narrow definition of rough sleeping, discussed above the survey still suggests that over 10,000 young people were sleeping rough each night-this still very high and suggests that further research would be helpful to see if these results can be replicated, possibly drawing on further surveys.

\subsection{Sofa Surfing}

The 2,011 young people aged 16-25 surveyed were asked:

"Thinking about 'sofa surfing' (where individuals stay with friends or members of their extended family on their floor or sofa as they have nowhere else to go), do you have any experience of doing this?"

Those who said yes, were then asked whether this experience was in the last year, or longer ago.

\footnotetext{
${ }^{3}$ The length of time spent rough sleeping was asked in bands. A conservative estimate has been used here by assuming all spent the lowest time for each band (e.g. 'more than a week but less than a month' has been assumed to be just eight nights). This means that the estimates of the proportion of young people sleeping rough on any one night and the total numbers sleeping rough are lowest possible estimates from the answers given in the survey.

${ }^{4}$ This has been calculated by dividing the total number of nights spent by the number of days in a year (365).
} 
Left a negative home envionment

Parents unable or unwilling to house

Friends or extended family unable or unwilling to house

Split from a partner

Tenancy ended though no fault

Overcrowding

Suffering domestic violence at the family home

Suffering substance abuse

Evicted for rent arrears

Suffering domestic violence from a partner

Left care

Not British and nowhere to stay

Left prison

Evicted for anti-social behaviour

Other

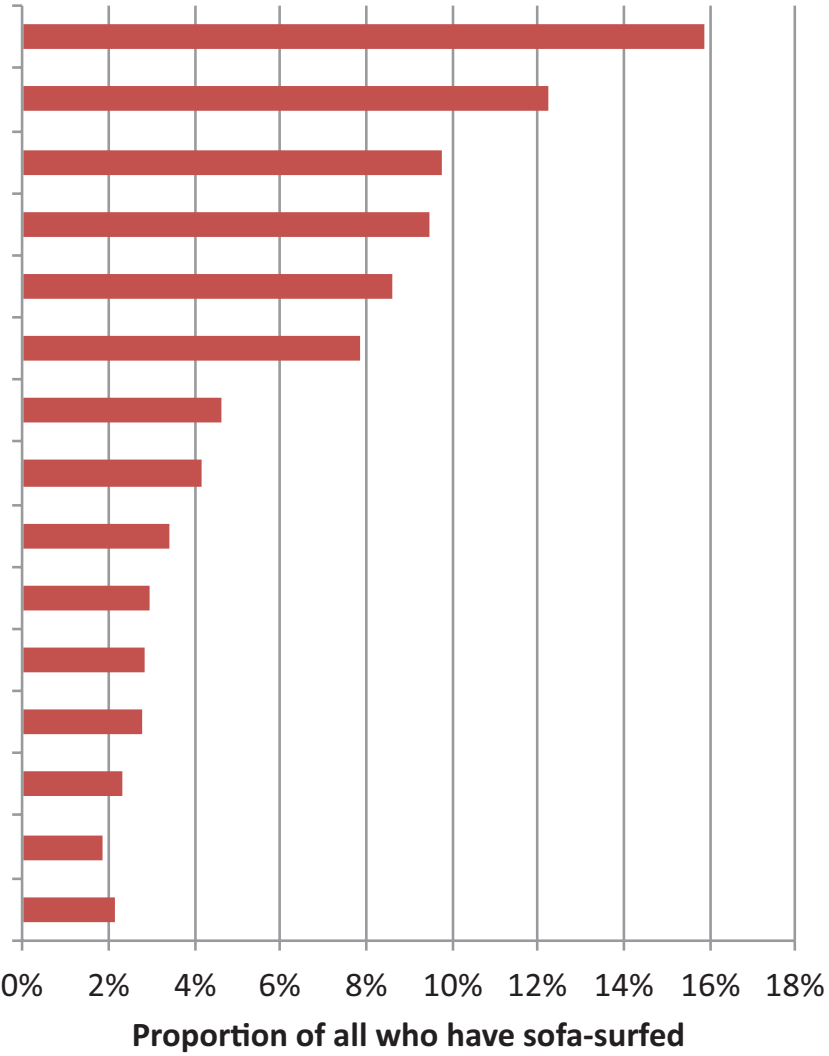

Figure 1. Reasons for sofa surfing among people aged 16-24 identified as sofa surfing in the year to September 2014. Source: Clarke et al. (2015). Respondents could only give one answer.

Overall, the survey suggested that 35 percent of young people in this age group (703 of the 2,011) had experience of sofa surfing, and 20 percent (409 people) had done so within the last year. In total 79 of the 409 people who had sofa surfed in the last year had also slept rough, meaning that a total of 675 out of the 2,011 (34 percent) had either sofa surfed or rough slept during the last twelve months. The survey explored the causes of sofa surfing (Figure 1).

As can be seen, the main reasons for young people sofa surfing relate to negative home environments or having been asked to leave by their parents. However there were substantial numbers also indicating that they had sofa surfed after a period of living independently, and were made homeless by a tenancy ending, splitting from a partner or no longer being able to stay with friends or extended family. Overcrowding was a reason in eight percent of cases.

The research found that some causes were associated with longer periods of sofa surfing. Overall, the median length of time that sofa surfers spent sofa surfing in the last 12 months was 25 days ( 3.5 weeks). Eighteen percent had sofa surfed for over three months, with four percent having done so for six or more out of the last twelve months. In contrast, 23 percent had sofa surveyed for a week or less. Figure 2 shows the relationship between the cause of sofa surfing reported the duration.

As can be seen, the reasons that are associated with having left home and then lost a home (evictions, leaving prison and domestic violence from a partner) are all associated with longer lengths of sofa surfing than are those associated with moving directly from the parental home to sofa surfing. This may suggest that for some young people a relatively short stay sofa surfing with a friend may be sufficient to enable them either to move back home or find a more permanent housing solution. In contrast, those who have lost a home of their own find it harder to move on from sofa surfing in a short timescale.

There were also significant differences between men and women, with men having sofa surfed for a median of five and a half weeks ( 38 days), as compared to two weeks (16 days) for women.

It is possible to make an estimate from the sofa surfing survey of the number of young people who are sofa surfing on any one night. Table 5 shows how this has been calculated.

The survey suggests that one in 35 young people of respondents were sofa surfing on any one night during the previous year. If the survey respondents are representative of the UK, this would equate to a total of 215,957 young people sofa surfing on any one night. As with the rough sleepers, it is hard to give a precise confidence interval to this estimate because some respondents contribute disproportionately to the total. If 57 people were responsible for all the sofa surfing this would give confidence limits of 160,379 to 272,319 young people sofa surfing on any one night. The fact that 409 people (not 57) actually contributed something to 


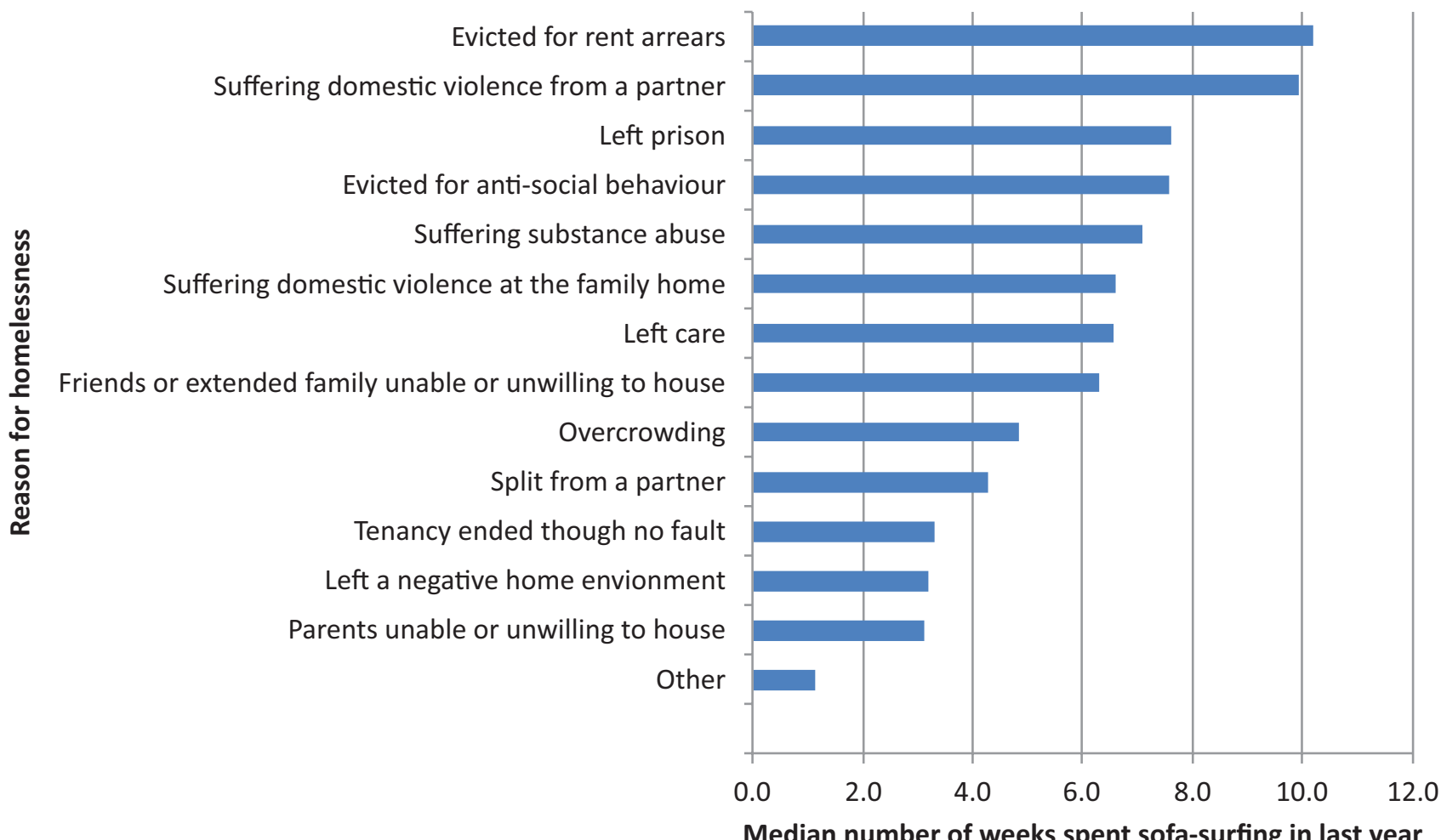

Figure 2. Median length of time spent sofa surfing by reason, among people aged 16-24 identified as sofa surfing in the year to September 2014. Source: Clarke et al. (2015).

Table 5. Estimated number of people aged 16-24 'sofa surfing' on any one night in the year to September 2014.

\begin{tabular}{lc}
\hline & UK \\
\hline Number of young people answering survey & 2,011 \\
Number who have sofa surfed during the last year [From survey] & 409 \\
Total number of sofa surfing nights in last year [Sum of all lengths of time sofa surfing by all respondents] & 20,977 \\
Average number sofa surfing on any one night during last year [Total number of sofa surfing nights $(20,977)$, & 57 \\
$\quad$ divided by total number of nights in the year (365)] & $2.9 \%$ \\
Proportion of young people sofa surfing on any one night [Average number sofa surfing on any one night (57) & \\
divided by number of young people answering survey (2,011)] &
\end{tabular}

the figure increases the level of confidence that the population total is closer to 215,957 .

The research explored whether certain groups of young people were more likely to have sofa surfed than others. Four key factors could be identified which were related to the likelihood of having sofa surfed, as shown in Figure 3.

The correlation coefficients were: Gender (0.262); Disabled (0.079); Ever in care or had social worker (0.273); Citizenship (0.102). All were significant the 0.01 confidence level.

As can be seen young men were substantially more likely than young women to have sofa surfed which is in contrast to the suggestions from previous research that women are more likely to sofa surf (Reeve \& Casey, 2006; Weber Sikich, 2008). However the biggest risk factor appears to be having had contact with the social care system as a child; 90 percent of those who had ever been in the care of a local authority or had a social worker as a child said that they had sofa surfed. Those without British citizenship or who were disabled were also significantly more likely to report having sofa surfed (Table 6).

Of those who had sofa surfed, men, non-British citizens, disabled people and those who had been in care or had a social worker as a child were also more likely to report having done so for longer lengths of time.

There was no statistically significant difference between the qualification level and whether people had sofa surfed. However, this may be somewhat complicated by the fact that many in this age group are still in education and still living at home; the teenagers in the survey were less likely than the early 20 s to have sofa surfed, and also more likely to lack qualifications. Comparing the qualification levels just of those in the older age groups (aged 22 or over) showed a clearer relationship between lacking qualifications and sofa surfing with 


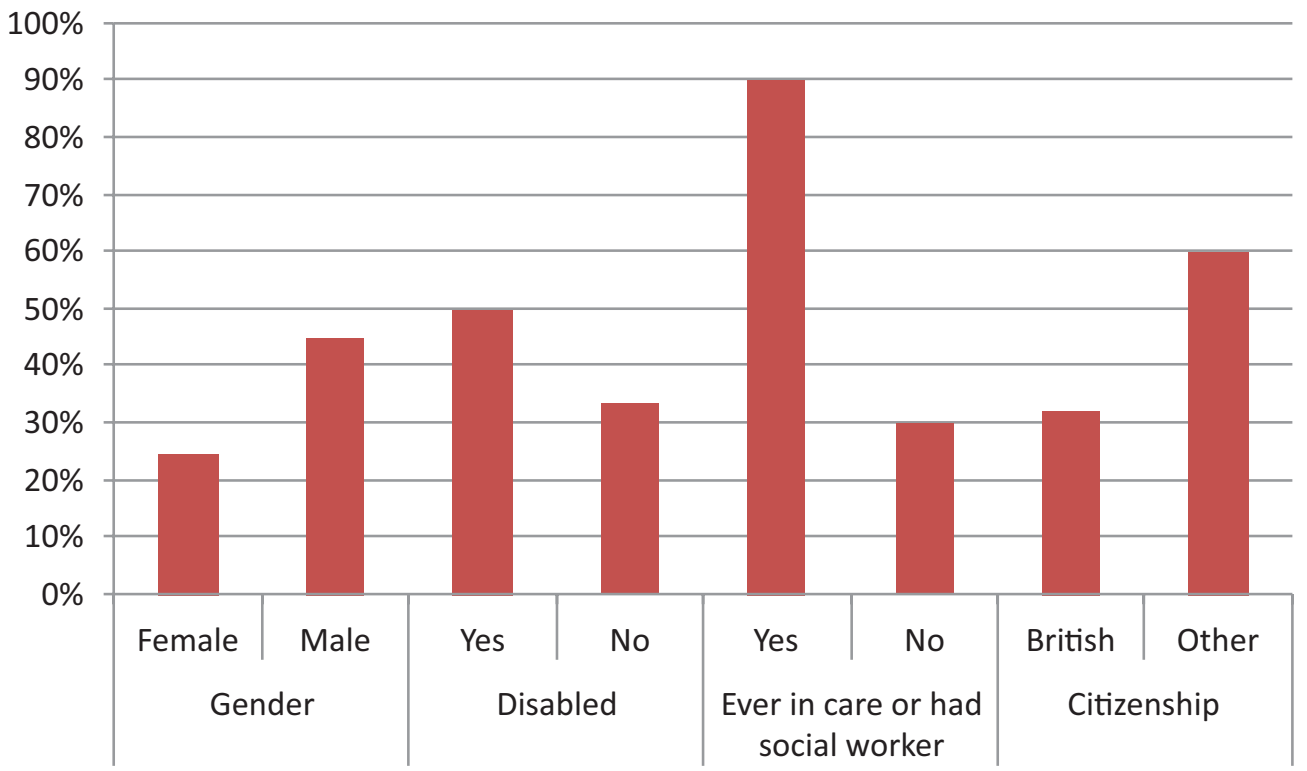

Figure 3. Extent of sofa surfing in different demographic groups, among people aged 16-24 identified as sofa surfing in the year to September 2014 ${ }^{5}$. Source: Clarke et al. (2015).

Table 6. Vulnerability indicators of young people who had slept rough or sofa surfers.

\begin{tabular}{|c|c|c|c|c|c|c|c|c|}
\hline & & $\begin{array}{l}\text { Ever } \\
\text { rough } \\
\text { slept }\end{array}$ & $\begin{array}{l}\text { Ever } \\
\text { sofa } \\
\text { surfed }\end{array}$ & $\begin{array}{l}\text { All } \\
\text { young } \\
\text { people }\end{array}$ & $\begin{array}{l}\text { Proportion } \\
\text { who have } \\
\text { ever slept } \\
\text { rough }\end{array}$ & $\begin{array}{l}\text { Proportion } \\
\text { who have } \\
\text { ever sofa } \\
\text { surfed }\end{array}$ & $\begin{array}{l}\text { Proportion } \\
\text { of rough } \\
\text { sleepers }\end{array}$ & $\begin{array}{l}\text { Proportion } \\
\text { of sofa } \\
\text { sufers }\end{array}$ \\
\hline \multirow{3}{*}{$\begin{array}{l}\text { Ever in care } \\
\text { or had social } \\
\text { worker }\end{array}$} & Yes & 134 & 142 & 158 & $85 \%$ & $90 \%$ & $25 \%$ & $20 \%$ \\
\hline & No & 391 & 550 & 1,833 & $21 \%$ & $30 \%$ & $73 \%$ & $78 \%$ \\
\hline & Don't know & 12 & 10 & 20 & $60 \%$ & $50 \%$ & $2 \%$ & $1 \%$ \\
\hline \multirow[t]{2}{*}{ Citizenship } & British citizen & 426 & 579 & 1,804 & $24 \%$ & $32 \%$ & $79 \%$ & $82 \%$ \\
\hline & Non-British citizen & 110 & 123 & 206 & $53 \%$ & $60 \%$ & $21 \%$ & $17 \%$ \\
\hline \multirow{6}{*}{$\begin{array}{l}\text { Employment } \\
\text { status }\end{array}$} & Full-time employment & 167 & 216 & 471 & $35 \%$ & $46 \%$ & $31 \%$ & $31 \%$ \\
\hline & Full-time student & 175 & 242 & 1,010 & $17 \%$ & $24 \%$ & $33 \%$ & $34 \%$ \\
\hline & Part-time employment & 73 & 98 & 191 & $38 \%$ & $51 \%$ & $14 \%$ & $14 \%$ \\
\hline & Part-time student & 40 & 45 & 88 & $45 \%$ & $51 \%$ & $7 \%$ & $6 \%$ \\
\hline & Self-employed & 17 & 22 & 43 & $40 \%$ & $51 \%$ & $3 \%$ & $3 \%$ \\
\hline & Unemployed & 57 & 70 & 187 & $30 \%$ & $37 \%$ & $11 \%$ & $10 \%$ \\
\hline \multirow[t]{3}{*}{ Disabled } & Yes & 68 & 78 & 158 & $43 \%$ & $49 \%$ & $13 \%$ & $11 \%$ \\
\hline & No & 449 & 602 & 1,800 & $25 \%$ & $33 \%$ & $84 \%$ & $86 \%$ \\
\hline & Prefer not to say & 20 & 22 & 52 & $38 \%$ & $42 \%$ & $4 \%$ & $3 \%$ \\
\hline \multirow[t]{6}{*}{ Qualifications } & None & 13 & 13 & 43 & $30 \%$ & $30 \%$ & $2 \%$ & $2 \%$ \\
\hline & Level 1/GCSE grade D-G & 44 & 62 & 88 & $50 \%$ & $70 \%$ & $8 \%$ & $9 \%$ \\
\hline & $A^{*}-\mathrm{C}$ GCSE & 111 & 135 & 475 & $23 \%$ & $28 \%$ & $21 \%$ & $19 \%$ \\
\hline & A level & 157 & 217 & 762 & $21 \%$ & $28 \%$ & $29 \%$ & $31 \%$ \\
\hline & BTEC & 44 & 58 & 143 & $31 \%$ & $41 \%$ & $8 \%$ & $8 \%$ \\
\hline & Degree/HND or above & 168 & 216 & 499 & $34 \%$ & $43 \%$ & $31 \%$ & $31 \%$ \\
\hline Total & & 536 & 703 & 2,011 & $27 \%$ & $35 \%$ & $100 \%$ & $100 \%$ \\
\hline
\end{tabular}

Source: Young people's survey, September 2014

\footnotetext{
5 'Other' citizenship status includes: Asylum seeker; Indefinite leave to remain; Discretionary leave; Limited leave to remain with refugee status; Limited leave-other; Citizen of another EEA country; Humanitarian Protection. The numbers within each of these categories were too small to be statistically significant themselves.
} 
57 percent of those lacking a degree having sofa surfed, compared with 40 percent of those with a degree (significant at the 0.01 confidence level).

Looking at the profile of rough sleepers and sofa surfers, however, it is clear that the large majority did not have any obvious vulnerabilities. Four out of five of sofa surfers had no prior involvement with the care system. And the large majority had British Citizenship, were not disabled and had left school with at least good General Certificate of Secondary Education (GCSE) grades (C and above). Nearly a third were graduates. This suggests that sofa surfing is not an uncommon experience for large numbers of young people from all backgrounds.

The research explored whether the young people felt that sofa surfing had had a negative or positive impact on various aspects of the respondent's life, as shown in Table 7.

As can be seen, there were very mixed views on this issue. Sofa surfing was often reported as a positive experience in most aspects of life, most likely because re- spondents were comparing to the situation they had left behind. Moving away from a home situation of conflict or severe overcrowding can help people to repair relationships with their families. Sofa surfing can also allow a young person to remain near a job or to move somewhere they hope to find work or housing.

Using the answers to the questions above, a 'positive rating' was created, using the sum of the scores given above (where 'very positive $=5$; fairly positive $=4$, etc.). The average score for all sofa surfers was 22.3 (Table 8).

Employment status was strongly correlated with positive views on sofa surfing, with an average rating of 19.3 for unemployed people, compared to 23.4 for full time students and 22.2 for employed people. This suggests that more vulnerable people with less secure employment or educational arrangements were more likely to find sofa surfing to be detrimental to their well-being.

Men were more positive than women, with average scores of 22.9 and 21.2 respectively. Young people who

Table 7. Impact of sofa surfing on the situation of people aged 16-24 identified as sofa surfing during the year to September 2014.

\begin{tabular}{llllllr}
\hline & Very negative & Fairly negative & Don't know & Fairly positive & Very positive & Total \\
\hline Education & $10 \%$ & $27 \%$ & $14 \%$ & $32 \%$ & $18 \%$ & $100 \%$ \\
Work & $13 \%$ & $27 \%$ & $11 \%$ & $34 \%$ & $16 \%$ & $100 \%$ \\
Relationships & $10 \%$ & $26 \%$ & $4 \%$ & $37 \%$ & $23 \%$ & $100 \%$ \\
Well-being & $15 \%$ & $31 \%$ & $6 \%$ & $30 \%$ & $19 \%$ & $100 \%$ \\
Physical health & $12 \%$ & $33 \%$ & $8 \%$ & $29 \%$ & $19 \%$ & $100 \%$ \\
Finding housing & $9 \%$ & $28 \%$ & $11 \%$ & $33 \%$ & $19 \%$ & $100 \%$ \\
Finances & $13 \%$ & $25 \%$ & $6 \%$ & $38 \%$ & $19 \%$ & $100 \%$ \\
\hline
\end{tabular}

Source: Clarke et al. (2015).

Table 8. 'Positive rating' for sofa surfing by demographic group.

\begin{tabular}{|c|c|c|c|c|}
\hline & Mean score & Std. Error & Significance & $\mathbf{N}$ \\
\hline All sofa surfers & 22.3 & & & 703 \\
\hline Female & 21.2 & .448 & $* * *$ & 244 \\
\hline Male & 22.9 & .313 & $* * *$ & 459 \\
\hline Aged under 22 & 22.7 & .403 & & 278 \\
\hline Aged 22 or over & 22.1 & .337 & & 425 \\
\hline Working (FT, PT or self-employed) & 22.2 & .370 & & 336 \\
\hline Unemployed & 19.3 & .827 & $* * *$ & 80 \\
\hline Students & 23.4 & .386 & $* * *$ & 287 \\
\hline Care leaver & 25.4 & 1.277 & & 34 \\
\hline Non-British citizen & 23.9 & .516 & & 124 \\
\hline Living in England & 22.6 & .284 & $* *$ & 568 \\
\hline Living in Scotland & 20.6 & .890 & $* *$ & 64 \\
\hline Living in Northern Ireland & 20.4 & 1.351 & & 25 \\
\hline Living in Wales & 22.4 & 1.071 & & 45 \\
\hline Living in London & 24.8 & 0.684 & $* * *$ & 106 \\
\hline Rough slept in last 12 months & 23.8 & .412 & $* * *$ & 296 \\
\hline Not rough slept in last 12 months & 19.8 & .516 & & 138 \\
\hline Sofa surfed under 3 months & 23.6 & .359 & & 335 \\
\hline Sofa surfed over 3 months & 24.6 & .970 & & 74 \\
\hline
\end{tabular}

Source: Young people's survey, September 2014 . Notes: ** Significant at $90 \%$ confidence; ${ }^{* * *}$ Significant at $95 \%$ confidence. 
had left care were more likely to report that sofa surfing had been a positive experience, with an average score of 25.4 , though this was not statistically significant. Young people currently living in London were also more positive about sofa surfing with an average score of 24.8 , possibly reflecting the more constrained housing options available in London and/or the value of being in London.

\section{Conclusions}

The findings from this research suggest that a third of young people have sofa surfed at some point, with a fifth having done so within the last year. If this survey is representative of the UK, it would suggest that around 1.5 million young people in the UK have sofa surfed within the last year. Estimates based on the survey would suggest that on any one night, a minimum of 216,000 young people are sofa surfing. Sofa surfing may, for some young people at least, not necessarily be a negative experience and can enable young people to move to a new area, or remain in their local area gaining or retaining access to education or employment. It may give young people a chance to repair relationships with their families and tends to be a short-term arrangement especially for young people who have had to leave the parental home. The emergence of websites such as couchsurfing.com, whilst targeted at travellers rather than people who are homeless, nevertheless highlights the positive way in which sharing living spaces can be seen. It may, as such, fulfil a necessary role in the transient and mobile nature of young people's lives. The extent to which sofa surfing was seen as a positive experience by young people responding to this survey presents a challenge to the way in which we conceptualise homelessness as necessarily negative and often damaging experience. The ways in which young people make choices over housing, maybe compromising housing security for other social goods (such as access to employment or breathing space to repair relationships) would benefit from further research.

It is harder to see rough sleeping in this same waysleeping in parks, abandoned buildings, car parks or the street clearly places young people in a very unsafe situation and must be seen as a crisis situation, even if shortlived. Yet this survey suggests it is also not uncommonexperienced by a quarter of young people at some point in their lives, and by 17 percent of them within the last year. Even looking more narrowly just at the 'outdoor' places, nine percent of young people said that they had slept in one of these during the last year. Estimates based on the survey would suggest that on any one night, around 40,000 young people are sleeping rough in one of the places listed. At a time when access to mainstream housing is getting ever harder for young people and the welfare safety net further withdrawn, this is clearly a concern, suggesting the housing situations of many young people may already be precarious.

These figures for hidden homelessness are high, and significantly higher than has been found previously; anal- ysis of official statistics for youth homelessness in the UK suggests a many-times lower figure of just 78,00080,000 young people experiencing homelessness, with just tiny numbers known to be sleeping rough, and no data at all on sofa surfing. This clearly merits further research, and highlights the potential shortcomings of relying on administrative data and rough sleepers' counts for quantifying something that by its nature does not necessarily bring people into contact with those who collect the data.

These findings also support the argument that homelessness is not the primary cause of other problems, as most of the young people surveyed were-at the time of the survey-in adequate housing, and in work or studying. The widespread prevalence of hidden homelessness by young people and mixed views on the impacts of sofa surfing suggest that these kinds of homelessness do not for most young people lead on to wider forms of social exclusion.

However, the findings also suggest that nor is homelessness necessarily a consequence of wider vulnerabilities, as both sofa surfing and rough sleeping are undertaken by a large number of households most of whom are not entering a period of long term homelessness, or experiencing wider social exclusion, and are doing so without the involvement of external agencies or hostels. It is possible that by avoiding formal homeless provision young people also avoid becoming part of the 'culture of homelessness' (Chamberlain \& Johnson, 2013; Ravenshill, 2008), and thereby avoid some of the other problems associated with homelessness and street lifestyles.

An important finding is also that the profile of young people surveyed here who had experienced homeless is significantly less vulnerable than found in other research (Quilgars et al., 2008) and quite different in profile to those suffering 'multiple exclusion homelessness (Fitzpatrick \& Johnsen, 2011). This suggests that homeless people who turn to local authorities or other agencies for support are significantly more vulnerable than other young people experiencing a temporary situation of homelessness.

The findings also present a challenge for the focus on UK homelessness policies-which have very much been framed around the prevention agenda for the last ten years. Preventing something that occurs on such a wide scale is clearly challenging. The research suggests that a focus on causation alone may not be sufficient as the numbers who experience homelessness at some point are substantial. The findings instead suggest that there might be merit in improving further our understanding of why some young people move swiftly out of homelessness, whilst others fail to find a quick route out and suffer longer term effects.

\section{Acknowledgments}

This research was supported by Centrepoint, the Youth Homeless Charity. The polling was undertaken by Com- 
Res. The author would like to thank Centrepoint and all the young people who took part in the survey.

\section{Conflict of Interest}

The author declares no conflict of interests.

\section{References}

Amore, K., Baker, M., \& Howden-Chapman, P. (2011). The ETHOS definition and classification of homelessness: An analysis. European Journal of Homelessness, 5(2), 19-37.

Benjaminsen, L., \& Christensen, I. (2007). Homelessness in Denmark 2007: National survey. Copenhagen: Det Nationale Forskningscenter for Velfard.

Busch-Geertsema, V. (2014). Housing First Europe: Results of a European social experimentation project. European Journal of Homelessness, 8(1), 13-28.

Chamberlain, C., \& Johnson, G. (2013). Pathways into adult homelessness. Journal of Sociology, 49(1), 6077.

Clarke, A., Burgess, G., Morris, S., \& Udagawa, C. (2015) Estimating the scale of youth homelessness in the UK. London: Centrepoint. Retrieved from http://cdn.basw.co.uk/upload/basw_101305-9.pdf

Cull, M., Platzer, H., \& Balloch, S. (2006). Out on my own: Understanding the experiences and needs of homeless lesbian, gay, bisexual and transgender youth. Brighton: Health and Social Policy Research Centre, University of Brighton.

Department for Communities and Local Government. (2011). Vision to end rough sleeping: No second night out nationwide. London: Department for Communities and Local Government.

Department for Communities and Local Government. (2014). Rough sleeping statistics England-Autumn 2014 official statistics. London: Department for Communities and Local Government.

Filipovič Hrast, M. (2014). Scaling up Housing First in Europe. European Journal of Homelessness, 8(2), 255260.

Fitzpatrick, S., \& Johnsen, S. (2011). Multiple exclusion homelessness in the UK: Key patterns and intersections. Social Policy and Society, 10(4), 501-512.

Fitzpatrick, S., Bramley, G., \& Johnson, S. (2012). Pathways into multiple exclusion homelessness in seven UK cities. Urban Studies, 50(1), 148-168.

Fitzpatrick, S., Pawson, H., Bramley, G., Wilcox, S., \& Watts, B. (2015). The homelessness monitor: England 2015. London: Crisis. Retrieved from http:// www.crisis.org.uk/data/files/publications/Homeless ness_Monitor_England_2015_final_web.pdf

Gaetz, S. (2014). Can Housing First work for youth? European Journal of Homelessness, 8(2), 159-176.

Hodgson, K. J., Shelton, K. H., \& van den Bree, M. B. (2014). Mental health problems in young people with experiences of homelessness and the relationship with health service use: A follow up study. Evidence Based Mental Health, 17(3), 76-80.

Hodgson, K. J., Shelton, K. H., van den Bree, M. B., \& Los, F. J. (2013). Psychopathology in young people experiencing homelessness: A systematic review. American Journal of Public Health, 103(6), 24-37.

Homeless Link. (2014a). oung and homeless 2013. London: Homeless Link.

Homeless Link. (2014b). No second night out across England. London: Homeless Link.

Hutson, S., \& Liddiard, M. (1994). Youth homelessness: The construction of a social issue. Basingstoke: Palgrave Macmillan.

Johnsen, S., \& Teixeira, L. (2010). Staircases, elevators and cycles of change: 'Housing First' and other housing models for homeless people with complex support needs. London: Crisis.

Kidd, S. A. (2004). "The walls were closing in and we were trapped": A qualitative analysis of street youth suicide. Youth Society, 36(1), 30-55.

Mackie, P. K. (2012) Housing pathways of disabled young people: Evidence for policy and practice. Housing Studies, 27(6), 805-821. doi:10.1080/ 02673037.2012.714464

Maher, C., \& Allen, M. (2014). What is preventing us from preventing homelessness? A review of the Irish National Preventative Strategy. European Journal of Homelessness, 8(2), 119-136.

McCay, E., \& Aiello, A. (2013). The need for early mental health intervention to strengthen resilience in streetinvolved youth. In S. Gaetz, B. O'Grady, K. Buccieri, J. Karabanow, \& A. Marsolais (Eds.), Youth homelessness in Canada: Implications for policy and practice (pp. 229-242). Toronto: Canadian Homelessness Research Network Press.

National Audit Office. (2005). More than a roof: Progress in tackling homelessness. London: National Audit Office.

Northern Irish Housing Executive. (2012). Homelessness strategy for Northern Ireland 2012-2017. Belfast: Northern Irish Housing Executive.

Patterson, M., Moniruzzaman, A., Frankish, C. J., \& Somers, J. (2012) Missed opportunities: Childhood learning disabilities as early indicators of risk among homeless adults with mental illness in Vancouver, British Columbia. BMJ Open, 2(6). doi:10.1136/ bmjopen-2012-001586

Pawson, H., Netto, G., Jones, C., Wager, F., Fancy, C., \& Lomax, D. (2007). Evaluating homelessness prevention. London: Communities and Local Government.

Quilgars, D. (2010). Youth homelessness. In E. O'Sullivan, V. Busch-Geertsema, D. Quilgars, \& N. Pleace (Eds.), Homeless research in Europe. Brussels: FEANTSA.

Quilgars, D., Fitzpatrick, S., \& Pleace, N. (2011). Ending youth homelessness: Possibilities, challenges and pratical solutions. London: Centrepoint.

Quilgars, D., Johnsen, S., \& Pleace, N. (2008). Youth homelessness in the UK: A decade of progress? York: Joseph Rowntree Foundation. 
Ravenshill, M. (2008). The culture of homelessness. Altershot: Ashgate.

Reeve, K., \& Batty, E. (2011). The hidden truth about homelessness: Experience of single homelessness in England. London: Crisis.

Reeve, K., \& Casey, R. (2006). Homeless women: Still being failed yet striving to survive. London: Crisis.

Scottish Government. (2013). Operation of the homeless persons legislation in Scotland 2012-2013. Edinburgh: Scottish Government.

Scottish Government. (2014). Youth homelessness analysis 2013-2014. Edinburgh: Scottish Government.

St Mungo's Broadway. (2014). Street to home, CHAIN annual report, 1st April 2013-31st March 2014. London: St Mungo's Broadway. Retrieved from www.mungos.org/documents/15617

Stone, J., Berrington, A., \& Falkingham, J. (2014). Gender, turning points and boomerangs: Returning home in young adulthood in Great Britain. Demography, 51(1), 257-276.

Thomson, R. (2009). Transitions to adulthood. In W. Taylor, R. Earle, \& R. Hester (Eds.), Youth justice handbook: Theory, policy and practice (pp. 23-33). Oxon: Routledge.

Weber Sikich, K. (2008). Global female homelessness: A multi-faceted problem. Gender Issues, 25(3), 147156.

Welsh Government. (2016). National rough sleeper count, November 2015-Experimental statisticsRevised (SDR 13/2016). Cardiff: Welsh Government.

\section{About the Author}

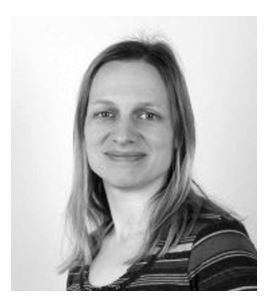

Anna Clarke is a Senior Research Associate at the Cambridge Centre for Housing and Planning Research, within the University of Cambridge (www.cchpr.landecon.cam.ac.uk), where she has worked since 2004. Her research interests include housing need, homelessness, demand for social housing and low cost home ownership, worklessness and a growing area of work around welfare reform. She has published work for a wide variety of funders including the UK government, the National Housing Federation, Shelter, Centrepoint and the Joseph Rowntree Foundation. 